\title{
Impulsivity across the course of bipolar disorder
}

\author{
Stephen M. Strakowski, MD ${ }^{1,3}$, David E. Fleck, PhD ${ }^{1}$, Melissa P. DelBello, MD ${ }^{1}$, Caleb M. \\ Adler, MD ${ }^{1,3}$, Paula K. Shear, PhD ${ }^{1,3}$, Renu Kotwal, MD ${ }^{1}$, and Stephan Arndt, PhD ${ }^{4}$ \\ ${ }^{1}$ Division of Bipolar Disorders Research, University of Cincinnati College of Medicine, Cincinnati \\ Ohio \\ 2 Psychopharmacology Program, University of Cincinnati College of Medicine, Cincinnati Ohio \\ 3 Department of Psychiatry, and the Center for Imaging Research, University of Cincinnati \\ College of Medicine, Cincinnati Ohio \\ ${ }^{4}$ Department of Psychiatry, University of lowa
}

\section{Abstract}

Objective-To determine whether abnormalities of impulse control persist across the course of bipolar disorder, thereby representing potential state markers and endophenotypes.

Methods-Impulse control of 108 bipolar I manic or mixed patients was measured on three tasks designed to study response inhibition, ability to delay gratification, and attention; namely a stop signal task, a delayed reward task, and a continuous performance task, respectively. Barrett Impulsivity Scale (BIS-11) scores were also obtained. Patients were then followed for up to one year and re-assessed with the same measures if they developed depression or euthymia. Healthy comparison subjects were also assessed with the same instruments on two occasions to assess measurement stability.

Results-At baseline, bipolar subjects demonstrated significant deficits on all three tasks as compared to healthy subjects, consistent with more impulsive responding in the bipolar manic/ mixed group. In general, performance on the three behavioral tasks normalized upon switching to depression or developing euthymia. In contrast, BIS-11 scores were elevated during mania and remained elevated as bipolar subjects developed depression or achieved euthymia.

Conclusions-Bipolar I disorder patients demonstrate deficits on laboratory tests of various aspects of impulsivity when manic, as compared to healthy subjects, that largely normalize with recovery and switching into depression. However, elevated BIS scores persist across phases of illness. These findings suggest that impulsivity has both affective-state dependent and trait components in bipolar disorder.

\section{Keywords}

Bipolar disorder; BIS; impulsivity; delayed reward; inattention; response inhibition

Impulsivity is a frequent component of the course and presentation of bipolar disorder; it has therefore been proposed to represent a core feature of the illness that persists across different affective states (1-8). However, impulsivity is a multi-faceted construct that cannot be defined by a single behavior. For example, based on studies with the Barratt Impulsiveness Scale (BIS), Barratt and colleagues suggested that impulsivity consists of three independent

Direct all correspondence to Stephen M. Strakowski, MD; Center for Imaging Research; University of Cincinnati College of Medicine; 231 Albert Sabin Way (ML0583), Cincinnati, OH 45267-0583. Telephone: 513-558-6225. Fax: 513-558-0187.

Stephen.Strakowski@uc.edu. 
behavioral factors $(9,10)$. These factors include: 1) Non-planning Impulsiveness, which refers to a present orientation or failure to consider the future; 2) Motor Impulsiveness, i.e., acting without thinking; and 3) Attentional Impulsiveness, which is a tendency to shift attention quickly, causing inappropriately rapid decisions. This work and that of others (e.g., 11-13) suggests that impulsivity is comprised of three components: 1) an inability to delay gratification, i.e., an inability to delay response for an immediate reward in order to gain a larger reward or prevent a negative consequence; 2) disinhibition, i.e., an inability to inhibit a prepotent response in favor of a better response; and 3) inattention, i.e., an inability to maintain attention to complete a particular task rather than being distracted to an alternative task (4). These three behavioral components of impulsivity appear to be independent and may be mediated by semi-independent neural systems (12).

We recently examined these three aspects of impulsivity during the manic phase of bipolar disorder (4). In order to assess these behaviors we employed a stop-signal task, delayed reward task, and a continuous performance task, respectively. We found that these three aspects of impulsivity were largely independent, were elevated in mania as compared with healthy subjects, and did not correlate with affective symptoms (4). These findings supported the proposal that impulsivity may represent a core trait of bipolar disorder that is independent of symptom severity (1-4). However, we also found that manic patients were more impulsive on the delayed reward task than mixed patients (4), suggesting that impulsivity may instead be related to affective state. In the absence of longitudinal measures within individual subjects, we could not resolve this apparent contradiction. Moreover, to our knowledge, no previous studies have longitudinally examined impulsivity in bipolar disorder, leaving the state or trait nature of these behaviors uncertain.

With these considerations in mind, the aim of the present study was to determine whether impulsivity observed during mania persists across phases of bipolar illness, in order to clarify whether impulsivity is independent of affective state. To achieve this aim, we administered the previously described tasks (4) and the Barratt Impulsiveness Scale (BIS-11)(9) to 108 bipolar subjects during an acute manic or mixed episode and then again as these subjects developed depression and achieved euthymia. We predicted that elevated ratings on the BIS-11 and impulsive responding on the behavioral tasks would longitudinally persist during depression and euthymia, consistent with the hypothesis that impulsivity is core trait of bipolar disorder.

\section{METHODS}

\section{Subjects}

The methods for this study have been reported previously (4), but will be discussed for context and extended to describe the longitudinal component not previously analyzed. Treatment-seeking patients with DSM-IV bipolar I disorder, manic or mixed $(\mathrm{N}=108)$, were recruited from the inpatient units and outpatient clinics of the University of Cincinnati Academic Health Center. Patients were required to meet DSM-IV criteria for bipolar disorder, currently in an acute manic or mixed episode. Bipolar subjects had an index Young Mania Rating Scale (YMRS) total score $\geq 20(4,16)$. Bipolar patients were excluded if the manic/mixed episode was secondary to drug or alcohol intoxication or withdrawal, or if it was not possible to determine from evaluation whether the bipolar illness was secondary to a substance use disorder based on DSM-IV criteria. They were not excluded by other psychiatric comorbidities. Healthy subjects $(\mathrm{N}=48)$ were recruited by advertisement and word-of-mouth from the surrounding communities. Smaller numbers of healthy subjects were recruited because the primary analyses were within the bipolar subjects (i.e., changes in impulsivity measures with changes in mood state). Therefore, this number of healthy subjects was based on a priori sample size estimates to provide sufficient numbers of 
subjects for comparison with the fraction of patients expected to develop depression or euthymia (approximately one-third) at a moderate effect size (Cohen's $d=0.4$ ) with power $=0.80$ and alpha $<0.05$. Healthy subjects had no personal history of any Axis I psychiatric disorder or any history of affective or psychotic disorders in first degree relatives. Both the healthy and bipolar groups were limited to an age range of 18 to 50 years in order to minimize age confounds on cognitive measures. Additionally, subjects were excluded if they had a medical or neurological disorder that might potentially impact task performance; by an estimated IQ score <85; or if they were exhibiting symptoms or signs of drug or alcohol intoxication or withdrawal. All subjects provided written informed consent after procedures had been explained in full. This study was approved by the Institutional Review Board of the University of Cincinnati. As noted, we previously reported results characterizing measures of impulsivity in acute mania from the first 70 bipolar subjects (4); however, the current report extends that work by adding subjects and by longitudinally examining changes within subjects across phases of illness.

\section{Clinical assessments}

A diagnosis in patients of bipolar I disorder, manic or mixed, or no Axis I diagnosis in healthy subjects, was established using the Structured Clinical Interview for DSM-IV Axis I Disorders, Patient version (SCID-I/P) $(4,17)$. Additionally, the lifetime occurrence of Attention Deficit Hyperactivity Disorder (ADHD) and current or past substance use disorders were identified with the SCID-I/P (4). Psychiatric symptom ratings were obtained at the index assessment and each monthly follow-up evaluation. As noted, the YMRS was used to assess manic symptoms. Depressive symptoms were assessed with the MontgomeryAsberg Depression Rating Scale (MADRS) (18). Additionally, the Addiction Severity Index (ASI) (19) was completed at each visit to document drug and alcohol use during the previous month. In this sample, rates of substance use disorders other than alcohol, cannabis, and cocaine were too infrequent to be evaluated statistically. Cocaine and cannabis were combined as 'drug use disorder' since cocaine use was infrequent and rarely occurred in the absence of cannabis abuse (4).

General measures of premorbid intellectual function (IQ) were obtained using the American Modification of the National Adult Reading Test (ANART) (20,21,41). Healthy subjects and bipolar patients achieving euthymia also received a more comprehensive assessment using the four-subtest version of the Wechsler Abbreviated Scale of Intelligence (WASI) (22). Demographic information was collected through direct interview and review of the medical records (4). Medications being taken at the time of the testing were categorized into general classes including: lithium, anti-epileptics, antipsychotics and antidepressants. Other medication classes were infrequently prescribed. Healthy subjects were not receiving psychotropic medications.

\section{Impulsivity assessments}

The behavioral tasks have been described previously (4). Bipolar subjects were tested at the index evaluation and again when they developed a major depressive episode or achieved euthymia. Healthy subjects were tested at the index evaluation and approximately 4 months later in order to evaluate measurement stability and potential repeated-testing effects.

\section{Disinhibition}

Disinhibition was assessed using the Logan Stop-Signal Task (SST), which has been well validated (24-28). Subjects were presented a letter (X or O) at one second intervals and responded by pressing a button corresponding to the displayed letter. During these trials, $25 \%$ of the 'go' signals were followed by an auditory 'stop' signal. The 'stop signal latency' was initially set at $250 \mathrm{msec}$ (i.e., the tone followed the presentation of the letter by 250 
msec), and then was either increased or decreased by $50 \mathrm{msec}$ on the next stop trial, depending on whether the participant did or did not stop successfully, respectively. Using this iterative procedure, the proportion of successful stop responses becomes fixed at approximately $50 \%$ for each participant.

Subjects were first given two sets of 32 practice trials to become familiarized with procedures. Then, participants completed four blocks of 64 trials (with 2-minute rest periods between blocks). Blocks were combined for analyses. The primary measure of interest was the "stop signal reaction time (SSRT)," calculated as the mean 'go' response time during trials with no stop signal minus the mean 'stop' signal latency when subjects successfully inhibited a response (4). Subject performances were excluded for insufficient effort if less than 50\% of the 'go' signals elicited a response and there were less than three successful 'stops'; these criteria were necessary for the task to converge while being fairly liberal to ensure full representation of response patterns. Eighty (73\%) of the bipolar and 38 (79\%) of the healthy subjects completed the index SST successfully. As reported previously in a large subset of these subjects, there were minimal differences in demographic and clinical variables between subjects who were and were not able to complete the SST at baseline (4).

\section{Inability to delay gratification}

A delayed reward task (DRT) was administered to assess subjects' ability to delay gratification. This task is based on an adjusting reward schedule similar to those that have been used in animal studies (42) as modified for humans by Cherek et al (29). Several previous studies support the task's validity (29-31). During the DRT, subjects were presented with two response options: 1) the letter ' $A$ ', which was the impulsive response, and 2) the letter 'B', which was the self-control response. Each letter was the same size presented in right and left mirror locations of the computer screen. Subjects used a computer mouse to select either A or B for each trial. When A was selected, the B was immediately removed from the screen, and after a fixed 5 second delay, the A started to flash. The subject was instructed to respond using the right mouse button while the letter was flashing in order to receive 5 cents added to a reward counter. If the subject selected $\mathrm{B}$, then the $\mathrm{A}$ was removed and after a variable delay, the B began to flash. Selecting the flashing B added a 15-cent reward to the counter. Because the number of trials was fixed, the maximal amount of money would be earned by always selecting response B. However, the length of the delay for response B was manipulated. Specifically, the initial delay for B was set at 15 seconds. Each time B was chosen, the delay for the next B choice was increased by 2 seconds. Each time A was chosen, the delay for the next B was decreased by 2 seconds to a minimum of 7 seconds, so that it was always greater than the delay for A ( 5 seconds). Ten training trials preceded the actual session to familiarize subjects with the procedures and apparatus of the task. Then, a total of 25 trials were completed at each session. Subjects controlled the rate of trial presentation, since one letter did not disappear until after the other was selected, and the trial did not re-set until the second button push while the selected letter was flashing. The primary measures of interest were the percent of impulsive ('A') responses and reaction time. All of the healthy subjects and $106(97 \%)$ of the bipolar subjects completed the task at the index evaluation.

\section{Inattention}

Inattention was measured using the degraded stimulus version of the CPT (DSCPT; 32). The DSCPT has been widely used to study attentional processing in healthy and psychiatric populations, including bipolar disorder $(15,33,34)$. In this task, subjects were presented a random series of numbers from 0 to 9 . Each number was displayed for $35 \mathrm{msec}$, and numbers were presented at a rate of one per second. The numbers were perceptually degraded (i.e., blurred) to increase the difficulty (32). Subjects responded to the target 
stimulus (the number 0 ) by pressing a button. A total of 480 trials were presented, including $25 \%$ targets, divided into six successive blocks presented over 8 minutes. Prior to the actual session, subjects were given a brief training session of one block ( 80 numbers). One measure of interest was sensitivity ( $\left.\mathrm{A}^{\prime}\right)$, which is a nonparametric measure analogous to discriminability $\left(\mathrm{d}^{\prime}\right)$ and refers to the ability to discriminate between signal and noise. It is calculated as: $\mathrm{A}^{\prime}=0.5+(\mathrm{y}-\mathrm{x})(1+\mathrm{y}-\mathrm{x}) / 4 \mathrm{y}(1-\mathrm{x})$, in which $\mathrm{x}$ is the probability of a false alarm and $y$ is the probability of a hit (33). Additionally, the nonparametric version of response bias $\left(\mathrm{B}^{\prime \prime}\right)$ was calculated. Response bias represents variables other than sensitivity that may influence performance, such as fatigue or motivation (33), and is calculated by: $\mathrm{B} "=\mathrm{y}(1-\mathrm{y})-$ $\mathrm{x}(1-\mathrm{x}) / \mathrm{y}(1-\mathrm{y})+\mathrm{x}(1-\mathrm{x})$. A smaller $\mathrm{B}$ " represents more impulsive responding. Finally, reaction time was calculated (34). Subjects who did not respond to at least two targets were excluded from analysis. Forty-seven (98\%) of the healthy subjects and 105 (96\%) of the bipolar subjects successfully performed this task at the index evaluation and were included in analyses of the DSCPT.

\section{BIS-11}

The Barratt Impulsiveness Scale (BIS-11; 9,10) was completed at the index assessment and after patients achieved euthymia or developed depression. Variables analyzed were the BIS total score and the $2^{\text {nd }}$ order factors: Attentional Impulsiveness, Motor Impulsiveness and Non-planning Impulsiveness. All of the healthy subjects and 98 (90\%) of the bipolar subjects completed the BIS-11 at the index evaluation; non-completers were either unwilling or unable to complete the task.

\section{Follow-up Assessments}

Bipolar subjects returned for monthly follow-up appointments for up to one year after the index evaluation. Seventy-nine (73\%) patients completed at least 3 months of follow-up. Fifty subjects (46\%) developed either depression or euthymia (seven developed both) during the year of follow-up; 17 subjects (16\%) completed the year without developing either of these phases of illness. The remaining 41 subjects (38\%) dropped out before the end of the twelve month period and did not develop depression or euthymia. During these appointments, symptom ratings were completed for the interval using previously published methods $(5,6,15)$ to determine whether patients achieved euthymia or developed depression. Patients were classified as euthymic if they achieved at least 8 contiguous weeks of YMRS ratings $<6$ and MADRS ratings $<10$, and also did not meet criteria for DSM-IV mood episodes. Patients were evaluated for depression if they demonstrated at least two weeks of MADRS ratings $>14$, and met DSM-IV criteria for a major depressive episode, but not a mixed episode as verified with the Affective Disorders Module of the SCID-I/P. If classified as depressed or euthymic, then behavioral tests and the BIS-11 were repeated, typically within 2-3 days. Patients were treated primarily by study physicians using standard treatment guidelines for bipolar disorder. Healthy subjects were tested at a second visit approximately four months after the initial assessment. Thirty-two healthy subjects (67\%) attended the second assessment; the remainder either could not be located or refused to return for follow-up assessments.

\section{Statistical Analyses}

Analyses were performed using the Statistical Analysis System (SAS) for the Personal Computer (SAS Institute, Cary, NC 2006). Contrasts between bipolar manic/mixed and healthy subjects at baseline were performed using ANCOVA, adjusting for rates of cooccurring ADHD and alcohol and drug use disorders in order to demonstrate elevated impulsivity in the bipolar subjects at baseline (4). In order to test the primary hypothesis that elevated measures of impulsivity persist across mood states, we used three approaches. First, within subject analyses were performed using paired t-tests contrasting measurements at 
baseline and after developing depression and euthymia. Second, we contrasted impulsivity measurements of bipolar subjects during depression and euthymia with healthy subject measurements using ANCOVA. Third, we calculated intraclass correlation coefficients (ICCs) across testing sessions to measure stability of assessments; differences among ICCs were compared using Fisher's r-to-z transformations. These three levels of planned comparisons were used to test our hypothesis. Namely, the primary hypothesis would be supported by high ICCs and the absence of significant within-subject changes across mood states, and by significant differences between all bipolar mood states and healthy subject values. Only seven subjects developed both depression and euthymia, so we did not compare across all three mood states within subjects. Other analyses were performed in order to extend or interpret the primary analyses or manage potential confounds; as these analyses are post-hoc, they should be viewed as exploratory and interpreted cautiously.

\section{RESULTS}

\section{Demographic and clinical characteristics}

The healthy and bipolar groups were generally well matched on demographic variables (Table 1). Years of education significantly differed between groups, although with similar IQ scores, the relevance of this two-year difference seems minimal. Moreover, there were no significant associations between education and any impulsivity measures $(|\mathrm{r}| \leq 0.11, \mathrm{p}>.18)$. As expected by exclusion criteria for healthy subjects, the bipolar group exhibited higher rates of ADHD and lifetime rates of alcohol and drug use disorders (Table 1). As noted, we adjusted for these co-occurring disorders.

\section{IMPULSIVITY MEASURES (Tables 2 \& 3)}

\section{Group differences in impulsivity measures at baseline}

In order to establish that bipolar manic/mixed subjects exhibited elevated measures of impulsivity relative to healthy subjects, performance at baseline on each behavioral task was compared between healthy and bipolar subjects. The groups significantly differed on essentially all impulsivity measures, as expected from our previous report (4). Specifically, the bipolar subjects exhibited significantly longer stop signal reaction times (SSRTs); more impulsive responses and slower reaction time on the delayed reward task; and lower sensitivity $\left(\mathrm{A}^{\prime}\right)$ and bias $\left(\mathrm{B}^{\prime \prime}\right)$ on the degraded-stimulus $\mathrm{CPT}$ (Table 2). Additionally, the bipolar group exhibited significantly elevated BIS-11 total and subscale scores (Table 3). These findings suggest a more impulsive response style during mania (4).

\section{Changes in impulsivity measurements after changes in mood state}

In order to examine stability of impulsivity measures with changes in mood state in the bipolar subjects, we compared task performance during acute mania (i.e., at baseline) with performance after developing euthymia or depression (Table 2). Thirty-one bipolar patients achieved euthymia within a mean of 26 weeks following the index episode ( $\mathrm{SD}=14$ weeks). Upon achieving euthymia, bipolar subjects demonstrated a significant decrease in stopsignal reaction time (SSRT) and in delayed reward task (DRT) impulsive responding, and a significant increase in bias ( $\left.\mathrm{B}^{\prime \prime}\right)$ during the degraded stimulus (DS) CPT (Table 2).

Additionally, DSCPT reaction time significantly increased. These changes are all consistent with a decrease in impulsivity. In a post-hoc analysis we examined correlations between changes in DSCPT reaction time with changes in bias $\left(\mathrm{B}^{\prime \prime}\right)$ and sensitivity $\left(\mathrm{A}^{\prime}\right)$ to determine whether the slower reaction time accounted for improvement in DSCPT performance. Changes in DSCPT reaction time were not significantly correlated with changes in sensitivity $[\mathrm{r}(30)=0.09 ; \mathrm{p}>.6]$, although exhibited a nonsignificant trend toward a correlation with changes in bias $[\mathrm{r}(30)=0.34, \mathrm{p}=.06]$. 
Twenty-six bipolar patients developed depression during follow-up within a mean of 15 weeks ( $\mathrm{SD}=10$ weeks). When depressed, bipolar subjects exhibited a significant decrease in stop-signal reaction time (SSRT) and a significant increase in sensitivity on the DSCPT with a nonsignificant trend toward an increase in bias $[\mathrm{t}(23)=1.8, \mathrm{p}=.09]$. As with euthymia, these changes are consistent with decreased impulsiveness on these tasks. During depression these patients showed increased reaction time on the DSCPT, although this change was not significantly correlated with improvements in sensitivity $[\mathrm{r}(24)=0.21, \mathrm{p}>.3]$ or bias $[\mathrm{r}(24)=$ $-0.12, \mathrm{p}>.5]$.

In those bipolar subjects who subsequently developed depression, there were no significant changes from index (manic/mixed) BIS-11 total or subscale scores (Table 3). Similarly, in those bipolar subjects who achieved euthymia, they continued to demonstrate BIS-11 scores similar to index scores except for a significant, although probably clinically meaningless, two-point decrease in the 'Attentional' subscale (Table 3).

\section{Differences between healthy and bipolar depressed and euthymic subjects}

As the second test of our hypothesis, we used ANCOVA to compare impulsivity measures from bipolar subjects who achieved euthymia or developed depression with healthy subjects. Upon developing depression, bipolar subjects continued to demonstrate more impulsive responding on the delayed reward task (DRT) than healthy subjects, but demonstrated no other significant differences on the behavioral tasks. BIS-11 total and all subscale scores remained significantly elevated in the depressed bipolar subjects as compared with healthy subjects (Table 3 ).

Upon achieving euthymia, bipolar subjects exhibited no significant differences from healthy subjects on any behavioral task (Table 2). BIS-11 total and all subscale scores, except the Attentional subscale score, remained significantly elevated in bipolar patients during euthymia as compared with healthy subjects (Table 3). Of note, after adjusting for rates of co-occurring syndromes, the baseline total BIS- 11 score $[\mathrm{F}(1,93)=4.6, \mathrm{p}=.04]$ and the Attentional subscale score $[\mathrm{F}(1,93)=4.8, \mathrm{p}=.03]$ in the bipolar subjects who achieved euthymia during follow-up was significantly lower than the baseline BIS-11 scores of the remaining bipolar subjects (Table 3 ).

\section{Stability of impulsivity measures across phase of illness in bipolar subjects}

As the final test of our primary hypothesis, we calculated intraclass correlation coefficients (ICC) for impulsivity measures in the bipolar subjects between baseline (manic/mixed) and each of the other two affective phases (Tables $2 \& 3$ ). In general, the stability of these tests between repeated sessions was modest for both bipolar and healthy groups, typically ranging from $0.50-0.75$. Moreover, the stability between phases of bipolar disorder was similar to that from repeated testing in healthy subjects, with three exceptions. Specifically, on the delayed reward task, reaction time was significantly less stable in the bipolar subgroups between baseline (manic) and repeated (euthymia and depression) assessments than in healthy subjects (Table 2). Additionally, stability of DSCPT sensitivity and the BIS-11 Attentional subscale were significantly lower between baseline and repeated testing in the euthymic subgroup than in healthy subjects.

\section{Healthy subjects' changes in measures upon repeated testing}

As a group, healthy subjects exhibited minimal changes with repeated testing, suggesting minimal practice effects between testing sessions (Table 2). The only significant change noted was improvement in DSCPT sensitivity $[\mathrm{t}(31)=2.2, \mathrm{p}=.04]$. However, within individual healthy subjects, test stability was modest as noted by the ICC values (Tables 2 and 3). These results suggest that, while group values were relatively constant, there were 
reciprocal changes in performance occurring individually, leading to the modest stability observed.

\section{Associations between changes in symptoms and impulsivity task measures}

We examined associations between changes in impulsivity measures and changes in symptoms as the bipolar subjects progressed from manic or mixed states to depression or euthymia. None of these correlations were significant $(|r|<0.30, p>.10)$.

\section{Associations among impulsivity measures (Tables 2\&3)}

At baseline, the BIS-11 total and subscale scores demonstrated no significant correlations with any behavioral measure $(|r|<0.16, p>.12)$. During euthymia, only bias from the degraded-stimulus (DS) CPT was significantly associated with 'Motor Impulsiveness' $[\mathrm{r}(27)=-0.44, \mathrm{p}=.02]$; none of the other measures demonstrated significant associations with the BIS-11 measures $(|\mathrm{r}|<0.16, \mathrm{p}>.12)$. In contrast, during depression, significant inverse correlations were observed between sensitivity from the DSCPT and all BIS measures [total score: $\mathrm{r}(24)=-0.59, \mathrm{p}=.0025$; Attentional subscale: $\mathrm{r}(24)=-0.44, \mathrm{p}=.03$; Motor subscale: $\mathrm{r}=$ $-0.41, \mathrm{p}=.05$; and Non-planning subscale: $\mathrm{r}=-0.54, \mathrm{p}=.007]$. No significant correlations between BIS-11 scores and measures from the other two tasks were observed in depression $(|\mathrm{r}|<0.36, \mathrm{p}>.11)$.

\section{Effects of co-occurring syndromes}

None of the behavioral task measures significantly differed between patients with or without a lifetime history of an alcohol use disorder $[\mathrm{F}(1,78-104)<1.2, \mathrm{p} \geq .25]$, a drug use disorder $[\mathrm{F}(1,78-104)<0.8, \mathrm{p}>.3]$, or ADHD $[\mathrm{F}(1,78-104)<2.2, \mathrm{p}>0.18]$. In contrast, baseline BIS-11 total and all subscale scores were significantly higher in bipolar subjects with a history of an alcohol use disorder, a drug use disorder, and ADHD (Table 3).

To extend this analysis we removed all subjects with a history of ADHD, an alcohol use disorder, or a drug use disorder to determine whether the effects of these co-occurring syndromes explained BIS-11 elevations in the bipolar sample. Removal of these subjects left 43 healthy subjects and 30 bipolar manic subjects at baseline. Of the latter, 14 developed depression and 7 developed euthymia. Even after removing subjects with co-occurring syndromes, and correspondingly reducing statistical power, at baseline the bipolar manic

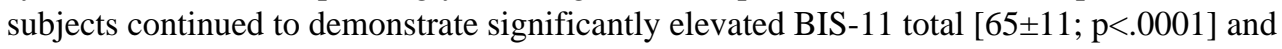
subscale scores [Attentional 17 $\pm 4, \mathrm{p}<.0001$; Motor 25 \pm 5 , $\mathrm{p}<.0001$; Non-planning 23 $\pm 6, \mathrm{p}=$. 003] compared with healthy subjects. Similarly, during depression the bipolar subjects continued to exhibit significantly elevated BIS-11 total [75 $\pm 9 ; \mathrm{p}<.0001]$ and subscale scores [Attentional 19 $\pm 3, \mathrm{p}<.0001$; Motor 25 $\pm 5, \mathrm{p}<.0001$; Non-planning 31 \pm 4 ] compared with health subjects. Finally, during euthymia, the bipolar subjects exhibited significantly elevated BIS-11 total [59 $\pm 12 ; \mathrm{p}=.01]$ and Motor [22 $\pm 5, \mathrm{p}=.01]$ and Non-planning [23 $\pm 6, \mathrm{p}=$. $02]$ subscale scores, although did not exhibit significantly elevated Attentional subscale scores [14 $\pm 4, p>.25]$, compared with healthy subjects.

\section{Effects of medications}

Medications prescribed are listed by subgroup in Table 1. Patients who developed depression exhibited no differences in types of medications prescribed at baseline compared to the remaining subjects $\left[\chi^{2}(1)<1.5, p>.2\right]$. At baseline, patients who achieved euthymia received more antipsychotics $\left[\chi^{2}(1)=5.3, p=.02\right]$, but otherwise showed no significant differences in rates of medications prescribed compared to the remaining subjects $\left[\chi^{2}(1)<1.8, p>.15\right]$. Because this observation, we re-analyzed the differences in baseline DSCPT reaction time in this subgroup with the remaining subjects. After adjusting for 
antipsychotic prescription, the differences between groups persisted [Table $2 ; \mathrm{F}(5,98)=4.1$, $\mathrm{p}=.045]$.

When euthymic, bipolar subjects demonstrated no significant differences in rates of prescription of any medication class compared to the baseline assessment [Table 1; $\left.\chi^{2}(1)<2.0, p>.15\right]$. In contrast, when depressed, they received significantly more anticonvulsants $\left[\chi^{2}(1)=4.3, \mathrm{p}=.04\right]$, antipsychotics $\left[\chi^{2}(1)=5.8, \mathrm{p}=.02\right]$, and antidepressants $\left[\chi^{2}(1)=4.1, p=.04\right]$ than at baseline. Changes in behavioral tasks between index (manic/ mixed) assessment and measures obtained during depression were therefore evaluated for associations with changes of medications using the Kruskal-Wallis test. There were no significant associations for anticonvulsants $\left[\chi^{2}(1)<2.3, p>.1\right]$ or antipsychotics $\left[\chi^{2}(1)<3.2\right.$, $\mathrm{p}>$.07]. However, depressed patients receiving antidepressants exhibited a greater decrease in delayed-reward task reaction time [ $573 \pm 809$ vs. $\left.237 \pm 1547 \mathrm{~ms} ; \chi^{2}(1)=4.7, \mathrm{p}=.03\right]$ and greater increase in DSCPT bias $\left[0.21 \pm 0.12\right.$ vs. $\left.0.07 \pm 0.34 ; \chi^{2}(1)=4.3, \mathrm{p}=.04\right]$ than patients not receiving antidepressants.

\section{DISCUSSION}

As expected from our previous report (4), we observed increased impulsivity in behavioral tasks and BIS-11 scores in acutely manic or mixed bipolar patients. However as bipolar individuals switched from mania to depression or euthymia, most of the behavioral task measures changed toward healthy values, even though not all of these changes achieved statistical significance. Additionally, in general, after bipolar subjects switched from mania, their performance on these behavioral tasks no longer significantly differed from healthy subjects. Moreover, although the current tasks in both the bipolar and healthy groups were only modestly stable across time, the bipolar subjects exhibited less stability in several measures. These findings fail to support our original hypothesis that impulsivity is a core feature of bipolar disorder. Consistent with these findings, in a cross-sectional study comparing manic and euthymic bipolar subjects, Swann and colleagues (1) found that commission errors (impulsive responses) on a memory task were elevated in the manic subgroup, but not the euthymic subgroup, as compared with healthy subjects. Together, these findings suggest that impulsivity as measured by these behavioral tasks is elevated only during mania and normalizes with depression or euthymia, i.e., that impulsiveness is a state-dependent characteristic of mania, rather than a trait of bipolar disorder. However, not all of the behavioral task measures supported this interpretation. Although the SSRT improved in euthymia, it remained significantly elevated compared to healthy subjects. Similarly, although DRT impulsive responding improved with depression, it too remained elevated relative to healthy subject performance. Consequently, the SSRT and DRT may identify both affective-state dependent and trait impulsivity components.

In contrast, supporting our hypothesis that impulsivity represents a core trait in bipolar disorder, elevated BIS-11 scores largely persisted within subjects across mood states. These longitudinal results validate prior cross-sectional findings by providing direct evidence that BIS-11 scores are elevated in bipolar individuals independent of affective state $(1,43-45)$. For example, Swann and colleagues administered the BIS-11 to 114 bipolar subjects in a variety of affective states and 71 healthy subjects (45). They found elevated BIS-11 scores in bipolar compared with healthy subjects, but found no differences in BIS-11 scores among mood states in the bipolar group. Because it is a self-report measure, the BIS-11 could potentially be sensitive to recall bias due to the influence of mood symptoms during mania or depression (e.g., inflated scores during mania or deflated scores during depression). The findings from this study suggest that bipolar subjects score the instrument similarly whether manic, depressed or euthymic, validating the robustness of this scale even in the presence of significant affective symptoms. 
Can these apparently discordant results be reconciled? In fact, the apparent discrepancies likely reflect differences among the instruments. The BIS-11 was specifically designed to capture trait impulsiveness reflected in 'real-life' behavior; specifically, in completing this self-report form, subjects rate their temperament (10). However, the BIS-11 is both an indirect and subjective measure. Since all of the bipolar subjects by definition experienced episodes of mania, these experiences may be incorporated within self-reported ratings of behavior, since separating affective symptoms from a bipolar individual's 'usual self' is not always straightforward (46-48). Consequently, affective symptoms might 'contaminate' ratings of 'usual' behavior. In the absence of directly observing behavior, it is difficult to eliminate this possibility. However, the BIS-11 has been shown to be elevated in a number of different types of impulsive conditions $(30,49-52)$. and, within bipolar subjects specifically, has been found to be more elevated with co-occurring substance abuse $(44,53)$, suicidality (54), and anxiety disorders (55). Indeed, within our sample, bipolar subjects with co-occurring ADHD and alcohol and drug use disorders exhibited higher BIS-11 scores; however, even after removing these subjects with co-occurring syndromes, the remaining bipolar patients exhibited elevated BIS-11 scores. Consequently, these elevations in BIS-11 scores are not simply due to co-occurring conditions that have impulsivity as a feature. Together, these findings provide face validity that the BIS-11 provides a measurement of 'real-life' trait impulsiveness, despite the limitations of a self-report.

In contrast to the indirect BIS-11 assessment, the behavioral tasks directly measure aspects of impulsive responding, although are limited to a specific time and a limited type of behavior. Moreover, it has not been established that impulsive responding on any of these tasks predicts 'real-life' impulsivity. Nonetheless, other studies have reported that subjects with histories of impulsive behaviors do respond more impulsively than healthy subjects on these or similar tasks, providing some support that laboratory measures may reflect 'reallife' activities $(30,50,53,56,57)$.

Although performance on the behavioral tasks normalized as bipolar subjects switched to depression or achieved euthymia, there were no significant correlations between symptom changes and task performance. These results suggest that task performance is not linearly related to symptom severity but, instead, is related to the presence of affective syndromes. In other words, it is the manic syndrome not manic symptoms that impacts task performance. This finding adds validity to a categorical rather than a dimensional approach to the phases of bipolar illness. However, the lack of association between symptoms and behavioral task performance could instead reflect inadequate sensitivity of either the rating scales or behavioral tasks to changes in symptoms. The modest stability of these tasks in all subgroups supports this interpretation. Consistent with these observations, Swann and colleagues (58) found that impulsive performance on a memory task was independent of mania ratings until a certain threshold of severity was met. However, inconsistent with our findings, after this threshold was met, they observed a correlation between manic symptom severity and task performance. The latter inconsistency may reflect differences in sensitivity between the symptom measures employed.

A potential confound in this study was medication exposure. We found minimal medication effects, particularly within the bipolar subjects who were typically receiving similar medications across testing sessions, consistent with our prior analysis of a manic subgroup from this sample (4). However, in the depressed subgroup we observed significant associations between taking antidepressants and changes consistent with improved task performance on the delayed reward task and degraded-stimulus continuous performance task (DSCPT). Whether this finding represents a direct antidepressant effect or is a reflection of the types of patient for whom antidepressants were prescribed could not be determined, since treatment decisions were naturalistic and clinically driven. Regardless, differences 
between healthy and bipolar subjects, and changes across time within bipolar subjects, did not appear to be directly related to medication effects in general.

As with all clinical research, limitations must be considered when interpreting findings. As noted, the instruments or tasks used may be insensitive to some aspects of impulsive behavior. The lack of stability across test sessions in these subjects introduces testing 'noise' that may make it difficult to identify 'signals' differentiating groups. Even the BIS-11, which is putatively a personality measure, was only modestly stable across repeated reporting sessions in bipolar and healthy subjects. Moreover, it is likely that impulsive behaviors occur across more than three dimensions. Consequently, components of impulsivity that bipolar individuals may experience during their course of illness may not have been measured in this study. Additional work with a broader array of tasks and symptom measures would help to address and extend this work. Finally, some subgroups of bipolar subjects that were examined to help interpret the primary findings (e.g., those who achieve euthymia and had a co-occurring history of ADHD) were relatively small. Findings from these smaller subgroups should be interpreted cautiously. Despite these limitations, to our knowledge this study represents the largest longitudinal evaluation to date of impulsivity across mood states in bipolar disorder.

With these considerations in mind, perhaps the most parsimonious interpretation of the apparent discrepancy between the BIS-11 and behavioral measures across mood states in bipolar disorder is that these tools simply measure different aspects of impulsivity by design. The BIS-11 measures personality traits and consequently in this study identified elevated trait impulsivity. In contrast, the behavioral tasks are designed to measure impulsive behavior within a specific time, and so consequently identified state-related impulsive responses (with the two exceptions noted). Taken together, the results of this study suggest that impulsiveness in bipolar disorder has both trait and state components; i.e. a baseline impulsive personality-style that becomes exaggerated (more impulsive) during mania, although not during depression (43).

A next step in this line of investigation might include developing direct measures of 'reallife' impulsive behavior to clarify further how tools such as those used in this study relate to the day-to-day experiences of bipolar individuals. For example, impulsive decision making within the context of interpersonal relationships has been minimally examined. Understanding impulsive behaviors within social contexts could have significant clinical relevance; e.g., this information could inform specific therapeutic interventions to manage interpersonal functional impairments and recovery, during and following affective episodes. Additionally, the results of this study suggest that laboratory measures of impulsivity may provide a marker of mania. Consequently, such measures may have a specific role for identifying early manic or hypomanic symptoms prior to the development of a full episode. They might also suggest the presence of co-occurring syndromes, encouraging more careful clinical assessment of comorbid ADHD, substance abuse and other impulse control disorders. If so, such illness course markers could help clinicians and bipolar individuals anticipate potential episodes, thereby intervening earlier and perhaps preventing significant illness exacerbation. Clearly, additional studies to examine the breadth and specificity of impulsive behaviors throughout the course of bipolar illness could advance our ability to better understand and manage these conditions.

\section{Acknowledgments}

This project was support by grants MH066626 and MH066626-03S1 (SMS), MH070849 (DEF), MH064086 (CMA), and MH063373 (MPD). The authors also acknowledge the programming provided by Kelly Jarvis. The authors have no competing or financial interests in the results reported. Full disclosure of all potential COIs, even though unrelated to this work, will be provided on Bipolar Disorders forms as required. 


\section{References}

1. Swann AC, Pazzaglia P, Nicholls A, Dougherty DM, Moeller FG. Impulsivity and phase of illness in bipolar disorder. J Affect Disord 2003 Jan;73(1-2):105-11. [PubMed: 12507743]

2. Moeller FG, Barratt ES, Dougherty DM, Schmitz JM, Swann AC. Psychiatric aspects of impulsivity. Am J Psychiatry 2001;158:1783-1793. [PubMed: 11691682]

3. Peluso MA, Hatch JP, Glahn DC, Monkul ES, Sanches M, Najt P, Bowden CL, Barratt ES, Soares JC. Trait impulsivity in patients with mood disorders. J Affect Disord 2007;100:227-231. [PubMed: 17097740]

4. Strakowski SM, Fleck DE, DelBello MP, Adler CM, Shear PK, McElroy SL, Keck PE Jr, Moss Q, Cerullo MA, Kotwal R, Arndt S. Characterizing impulsivity in mania. Bipolar Disorders 2009;11:41-51. [PubMed: 19133965]

5. Strakowski SM, DelBello MP, Fleck DE, Arndt S. The impact of substance abuse on the course of bipolar disorder. Biol Psychiatry 2000;48:477-485. [PubMed: 11018221]

6. Dunayevich E, Sax KW, Keck PE Jr, McElroy SL, Sorter MT, McConville BJ, Strakowski SM. Twelve month outcome in bipolar patients with and without a personality disorder. J Clin Psychiatry 2000;61:134-139. [PubMed: 10732661]

7. McElroy SL, Pope HG Jr, Keck PE Jr, Hudson JI, Phillips KA, Strakowski SM. Are impulse-control disorders related to bipolar disorder? Compr Psychiatry 1990;37:229-240. [PubMed: 8826686]

8. Larson ER, Shear PK, Krikorian R, Welge J, Strakowski SM. Working memory and inhibitory control among manic and euthymic patients with bipolar disorder. J Int Neuropsychol Soc 2005;11:163-172. [PubMed: 15962704]

9. Barratt, ES. Impulsivity: Integrating cognitive, behavioral, biological, and environmental data. In: McCown, WG.; Johnson, JL.; Shure, MB., editors. The Impulsive Client: Theory, Research and Treatment. Washington, D.C: American Psychological Association; 1993.

10. Patton JH, Stanford MS, Barratt ES. Factor structure of the Barratt Impulsiveness Scale. J Clin Psychol 1995;51:768-774. [PubMed: 8778124]

11. Dickman, SJ. Impulsivity and information processing. In: McCown, WG.; Johnson, JL.; Shure, MB., editors. The Impulsive Client: Theory, Research and Treatment. Washington, D.C: American Psychological Association; 1993.

12. Evenden JL. Varieties of impulsivity. Psychopharmacology (Berlin) 1999;146:348-361. [PubMed: 10550486]

13. Eysenck, HJ.; Eysenck, MW. Personality and individual differences: a natural science approach. New York: Plenum Press; 1985.

14. Bearden CE, Hoffman KM, Cannon TD. The neuropsychology and neuroanatomy of bipolar affective disorder: a critical review. Bipolar Disorders 2001;3:106-150. [PubMed: 11465675]

15. Sax KW, Strakowski SM, Keck PE Jr, McElroy SL, West SA, Stanton SP. Symptom correlates of attentional improvement following hospitalization for a first episode of affective psychosis. Biol Psychiatry 1998;44:784-786. [PubMed: 9798084]

16. Young RC, Biggs JT, Ziegler VE, Meyer DA. A rating scale for mania: reliability, validity and sensitivity. Br J Psychiatry 1978;133:429-435. [PubMed: 728692]

17. First, MB.; Spitzer, RL.; Gibbon, M.; Williams, JBW. Biometrics Research Department. New York State Psychiatric institute; 722 West 168th Street, New York, NY 10032: 1995. Structured Clinical Interview for DSM-IV Axis I Disorders- Patient Editions (SCID-I/P).

18. Montgomery SA, Asberg M. A new depression scale designed to be sensitive to change. $\mathrm{Br} \mathbf{J}$ Psychiatry 1979;134:382-389. [PubMed: 444788]

19. McClellan AT, Kushner H, Metzger D, et al. The fifth edition of the Addiction Severity Index. J Sub Abuse Treatment 1992;9:199-213.

20. Grober E, Sliwinski M. Development and validation of a model for estimating premorbid intelligence in the elderly. J Clin Exp Neuropsychol 2001;13:933-949. [PubMed: 1779032]

21. Nelson HE, Pantelis C, Carruthers K, Speller J, Baxendale S, Barnes TR. Cognitive functioning and symptoms in chronic schizophrenia. Psychol Med 1990;20:357-365. [PubMed: 2356261]

22. Wechsler, D. Wechsler Abbreviated Scale of Intelligence. San Antonio, TX: Harcourt Brace, Inc; 1999. 
23. Cohen JD, MacWhinney B, Flatt M, Provost J. PsyScope A: new graphic interactive environment for designing psychology experiments. Behav Res Methods Instruments Computers 1993;25:257271.

24. Logan GD, Cowan WB, Davis KA. On the ability to inhibit simple and choice reaction time responses: A model and a method. J Exp Psychology Hum Perceptual Performance 1984;10:276292.

25. Schachar R, Logan GD. Impulsivity and inhibitory control in normal development and childhood psychopathology. Dev Psychology 1990;26:710-720.

26. Logan, GD. On the ability to inhibit thought and action: a users' guide to the sop signal paradigm. In: Dagenbach, D.; Carr, TH., editors. Inhibitory Processes in Attention, Memory, and Language. Academic Press; San Diego: 1994. p. 189-239.

27. Logan GD, Schachar RJ, Tannock R. Impulsivity and inhibitory control. Psychological Science 1997;8:60-64.

28. Nigg JT. The ADHD response-inhibition deficit as measured by the Stop Task: replication with DSM-IV combined type, extension and qualification. J Abnormal Child Psychology 1999;27:393402.

29. Cherek DR, Lane SD. Laboratory and psychometric measurements of impulsivity among violent and nonviolent female parolees. Biol Psychiatry 1999;46:273-280. [PubMed: 10418703]

30. Dougherty DM, Bjork JM, Huckabee HCG, Moeller FG, Swann AC. Laboratory measures of aggression and impulsivity in women with borderline personality disorder. Psychiatry Res 1999;85:315-326. [PubMed: 10333383]

31. Cherek DR, Moeller FG, Dougherty DM, Rhoades H. Studies of violent and nonviolent male parolees: II. Laboratory and psychometric measurements of impulsivity. Biol Psychiatry 1997;41:514-522. [PubMed: 9046983]

32. Neuchterlein KH. Signal detection in vigilance tasks and behavioral attributes among offspring of schizophrenic mothers and among hyperactive children. J Abnormal Psychol 1983;92:4-28.

33. Sax KW, Strakowski SM, McElroy SL, Keck PE Jr, West SA. Attention and formal thought disorder in mixed and pure mania. Biol Psychiatry 1995;37:420-423. [PubMed: 7772653]

34. Fleck DE, Sax KW, Strakowski SM. Reaction time measures of sustained attention differentiate bipolar disorder from schizophrenia. Schizophrenia Res 2001;52:251-259.

35. Cohen, J. Statistical power analysis for the behavioral sciences. New York: Academic Press; 1977.

36. Pachet AK, Wisniewski AM. The effects of lithium on cognition: an updated review. Psychopharmacology (Berl) 2003;170:225-234. [PubMed: 14504681]

37. Haruno M, Kawato M. Different neural correlates of reward expectation and reward expectation error in the putamen and caudate nucleus during stimulus-action-reward association learning. $\mathrm{J}$ Neurophysiol 2006;95:948-959. [PubMed: 16192338]

38. Hampton AN, O'Doherty JP. Decoding the neural substrates of reward-related decision making with functional MRI. Proc Natl Acad Sci USA 2007;104:1377-1382. [PubMed: 17227855]

39. Strakowski SM, DelBello MP, Adler CM. The functional neuroanatomy of bipolar disorder: a review of neuroimaging findings. Molecular Psychiatry 2005;10:105-116. [PubMed: 15340357]

40. Wilder-Willis KE, Sax KW, Rosenberg HL, Fleck DE, Shear PK, Strakowski SM. Persistent attentional dysfunction in remitted bipolar disorder. Bipolar Disord 2001;3:58-62. [PubMed: 11333063]

41. Lebowitz BK, Shear PK, Steed MA, Strakowski SM. Stability of estimated IQ across mood state in patients with bipolar disorder. Bipolar Disorders 2006;8:81-84. [PubMed: 16411984]

42. Mazur, JE. An adjusting procedure for studying delayed reinforcement. In: Commons, ML.; Nevin, JA.; Rachlin, H., editors. Quantitative Analyses of Behavior. Vol. 5. Hillsdale, NJ: Lawrence Erlbaum, Assoc; 1987. p. 55-73.

43. Swann AC, Anderson JC, Dougherty DM, Moeller FG. Measurement of inter-episode impulsivity in bipolar disorder. Psychiatry Research 2001;101:195-197. [PubMed: 11286822]

44. Swann AC, Dougherty DM, Pazzaglia PJ, Pham M, Moeller G. Impulsivity: a link between bipolar disorder and substance abuse. Bipolar Disorders 2004;6:204-212. [PubMed: 15117399] 
45. Swann AC, Lijffijt M, Lane SD, Steinberg JL, Moeller FG. Increased trait-like impulsivity and course of illness in bipolar disorder. Bipolar Disorders 2009;11:280-288. [PubMed: 19419385]

46. Knowles R, Tai S, Jones SH, Highfield J, Morriss R, Bentall RP. Stability of self-esteem in bipolar disorder: comparisons among remitted bipolar patients, remitted unipolar patients and healthy controls. Bipolar Disorders 2007;9:490-495. [PubMed: 17680919]

47. Akiskal HS, Kilzieh N, Maser JD, Clayton PJ, Schettler PJ, Shea M, Endicott J, Schetfner W, Hirschfeld RM, Keller MB. The distinct temperament profiles of bipolar I, bipolar II and unipolar patients. J Affect Disorders 2006;92:19-33. [PubMed: 16635528]

48. Judd LL, Akiskal HS, Schettler PJ, Endicott J, Maser J, Solomon DA, Leon AC, Rice JA, Keller MB. The long-term natural history of the weekly symptomatic status of bipolar I disorder. Arch Gen Psychiatry 2002;59:530-537. [PubMed: 12044195]

49. Wu CS, Liao SC, Lin KM, Tseng MM, Wu EC, Liu SK. Multidimensional assessments of impulsivity in subjects with history of suicidal attempts. Compr Psychiatry 2009;50:315-321. [PubMed: 19486729]

50. Swann AC, Lijffijt M, Lane SD, Steinberg JL, Moeller FG. Trait impulsivity and response inhibition in antisocial personality disorder. J Psychiatr Res. 2009 [epub].

51. Cao F, Su L, Liu T, Gao X. The relationship between impulsivity and internet addiction in a sample of Chinese adolescents. Eur Psychiatry 2007;22:466-471. [PubMed: 17765486]

52. Fuentes D, Tavares H, Artes R, Gorenstein C. Self-reported and neuropsychological measures of impulsivity in pathological gambling. J Int Neuropsychol Soc 2006;12:907-912. [PubMed: 17064453]

53. Holmes KM, Bearden CE, Barguil M, Fonseca M, Monkul SE, Nery FG, Soares JC, Mintz J, Glahn DC. Conceptualizing impulsivity and risk taking in bipolar disorder: importance of a history of alcohol abuse. Bipolar Disorders 2009;11:33-40. [PubMed: 19133964]

54. Swann AC, Dougherty DM, Pazzaglia PJ, Pham M, Steinberg JL, Moeller FG. Increased impulsivity associated with severity of suicide attempt history in patients with bipolar disorder. Am J Psychiatry 2005;162:1680-1687. [PubMed: 16135628]

55. Taylor CT, Hirshfeld-Becker DR, Ostacher MJ, Chow CW, LeBeau RT, Pollack MH, Nierenberg AA, Simon NM. J Anxiety Disord 2008;22:868-876. [PubMed: 17936573]

56. Swann AC, Lijffijt M, Lane SD, Steinberg J, Moeller FG. Severity of bipolar disorder is associated with impairment of response inhibition. J Affect Disord 2009;116:30-36. [PubMed: 19038460]

57. Dougherty DM, Bjork JM, Harper RA, Marsh DM, Moeller FG, Mathias CW, Swann AC. Behavioral impulsivity paradigms: a comparison in hospitalized adolescents with disruptive behavior disorders. J Child Psychol Psychiatry 2003;44:1145-1157. [PubMed: 14626456]

58. Swann AC, Moeller GF, Steinberg JL, Schneider L, Barratt ES, Dougherty DM. Manic symptoms and impulsivity during bipolar depressive episodes. Bipolar Disorders 2007;9:206-212. [PubMed: 17430294] 


\section{Table 1}

Demographic and clinical variables of bipolar manic/mixed and healthy subjects participating in a longitudinal study of impulsivity.

\begin{tabular}{|c|c|c|c|c|}
\hline \multirow[b]{2}{*}{ Characteristic } & \multirow[b]{2}{*}{ Healthy Subjects $(\mathrm{N}=\mathbf{4 8})$} & \multirow{2}{*}{$\begin{array}{c}\text { All } \\
\text { Bipolar } \\
\text { Subjects } \\
(\mathbf{N}=108)\end{array}$} & \multicolumn{2}{|c|}{ Bipolar subgroups who: } \\
\hline & & & Developed Depression $(\mathrm{N}=26)$ & Developed Euthymia ( $\mathbf{N}=\mathbf{3 1}$ ) \\
\hline Age, yrs. & $31(9)$ & $29(10)$ & $29(9)$ & $29(10)$ \\
\hline Sex, $N(\%)$ women & $29(60)$ & $58(54)$ & $14(54)$ & $16(52)$ \\
\hline Ethnicity, $\mathrm{N}(\%)$ white & $39(81)$ & $77(71)$ & $24(92)$ & $23(74)$ \\
\hline Education, yrs. & $15(2)$ & $13(2)^{a}$ & $14(2)$ & $14(3)$ \\
\hline IQ & $107(10)$ & $108(18)$ & $115(23)^{g}$ & $109(12)$ \\
\hline YMRS, baseline & $1(2)$ & $26(6)^{b}$ & $25(6)$ & $26(4)$ \\
\hline - follow-up & $\mathrm{n} / \mathrm{a}$ & $\mathrm{n} / \mathrm{a}$ & $10(7)^{h}$ & $1(1)^{k}$ \\
\hline MADRS, baseline & $1(1)$ & $14(9)^{c}$ & $19(9)^{i}$ & $12(8)$ \\
\hline - follow-up & $\mathrm{n} / \mathrm{a}$ & $\mathrm{n} / \mathrm{a}$ & $23(8)^{j}$ & $1(1)^{l}$ \\
\hline Alcohol Use Disorder, N(\%) & $5(10)$ & $52(48)^{d}$ & $13(50)$ & $11(35)$ \\
\hline $\begin{array}{l}\text { Current (prior } 30 \text { days) } \\
\mathrm{N}(\%)\end{array}$ & $0(0)$ & $8(7)$ & $1(4)$ & $2(6)$ \\
\hline Drug Use Disorder, N(\%) & $2(4)$ & $48(44)^{e}$ & $13(50)$ & $7(23)^{m}$ \\
\hline $\begin{array}{l}\text { Current (prior } 30 \text { days) } \\
\mathrm{N}(\%)\end{array}$ & $0(0)$ & $15(14)$ & $3(12)$ & $3(10)$ \\
\hline ADHD, $N(\%)$ & $0(0)$ & $43(40)^{f}$ & $10(38)$ & $4(13)^{n}$ \\
\hline \multicolumn{5}{|l|}{ Medications prescribed, $\mathrm{N}(\%)^{*}$} \\
\hline Lithium, baseline & $\mathrm{n} / \mathrm{a}$ & $17(16)$ & $3(12)$ & $4(13)$ \\
\hline Lithium, follow-up & $\mathrm{n} / \mathrm{a}$ & $\mathrm{n} / \mathrm{a}$ & $8(31)$ & $2(6)$ \\
\hline Anti-epileptic, baseline & $\mathrm{n} / \mathrm{a}$ & $25(23)$ & $5(19)$ & $8(26)$ \\
\hline Anti-epileptic, follow-up & $\mathrm{n} / \mathrm{a}$ & $\mathrm{n} / \mathrm{a}$ & $12(46)$ & $13(42)$ \\
\hline Antipsychotic, baseline & $\mathrm{n} / \mathrm{a}$ & $69(64)$ & $14(54)$ & $25(81)$ \\
\hline Antipsychotic, follow-up & $\mathrm{n} / \mathrm{a}$ & $\mathrm{n} / \mathrm{a}$ & $22(85)$ & $28(90)$ \\
\hline Antidepressant, baseline & $\mathrm{n} / \mathrm{a}$ & $5(5)$ & $1(4)$ & $1(3)$ \\
\hline Antidepressant, follow-up & $\mathrm{n} / \mathrm{a}$ & $\mathrm{n} / \mathrm{a}$ & $6(23)$ & $4(13)$ \\
\hline None, baseline & $48(100)$ & $27(25)$ & $8(31)$ & $5(16)$ \\
\hline None, follow-up & $32(100)$ & $\mathrm{n} / \mathrm{a}$ & $1(4)$ & $1(3)$ \\
\hline
\end{tabular}

Abbreviations: IQ = intelligence quotient; YMRS=Young Mania Rating Scale; MADRS=Montgomery-Asberg Depression Rating Scale; $\mathrm{ADHD}=$ attention deficit hyperactivity disorder.

Some patients were receiving more than one medication

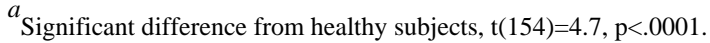

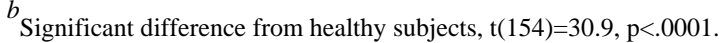

${ }^{c}$ Significant difference from healthy subjects, $\mathrm{t}(154)=10.4, \mathrm{p}<.0001$.

${ }^{d}$ Significant difference from healthy subjects, $\chi^{2}(1)=20.4, \mathrm{p}<.0001$. 
${ }^{e}$ Significant difference from healthy subjects, $\chi^{2}(1)=24.8, \mathrm{p}<.0001$.

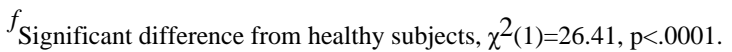

${ }^{g}$ Significant difference from remaining bipolar subjects, $\mathrm{t}(106)=2.2, \mathrm{p}=.03$.

${ }^{h}$ Mean YMRS score when depressed, significant change from baseline, $\mathrm{t}(25)=9.1, \mathrm{p}<.0001$.

${ }^{i}$ Significant difference from remaining manic subjects, $\mathrm{t}(106)=3.4, \mathrm{p}=.0009$.

${ }^{j}$ Mean MADRS score when depressed, nonsignificant change from baseline, $\mathrm{t}(25)=1.9, \mathrm{p}=.065$.

${ }^{k}$ Mean YMRS score when euthymic; significant change from baseline, $\mathrm{t}(30)=32.2, \mathrm{p}<.0001$.

${ }^{l}$ Mean MADRS score when euthymic; significant change from baseline, $\mathrm{t}(30)=6.7, \mathrm{p}<.0001$.

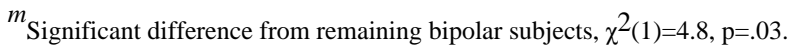

${ }^{n}$ Significant difference from remaining bipolar subjects, $\chi^{2}(1)=7.8, \mathrm{p}=.005$. 


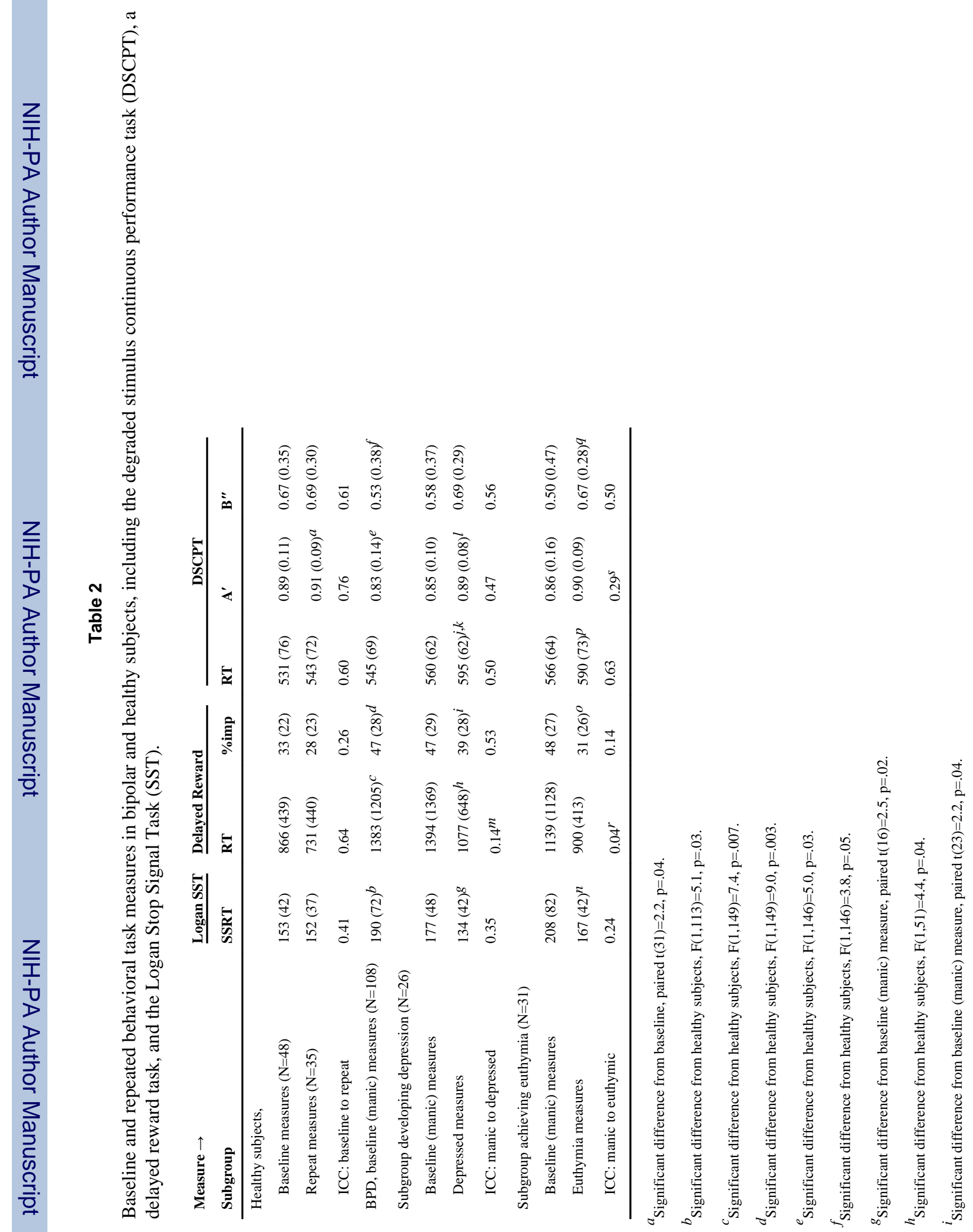




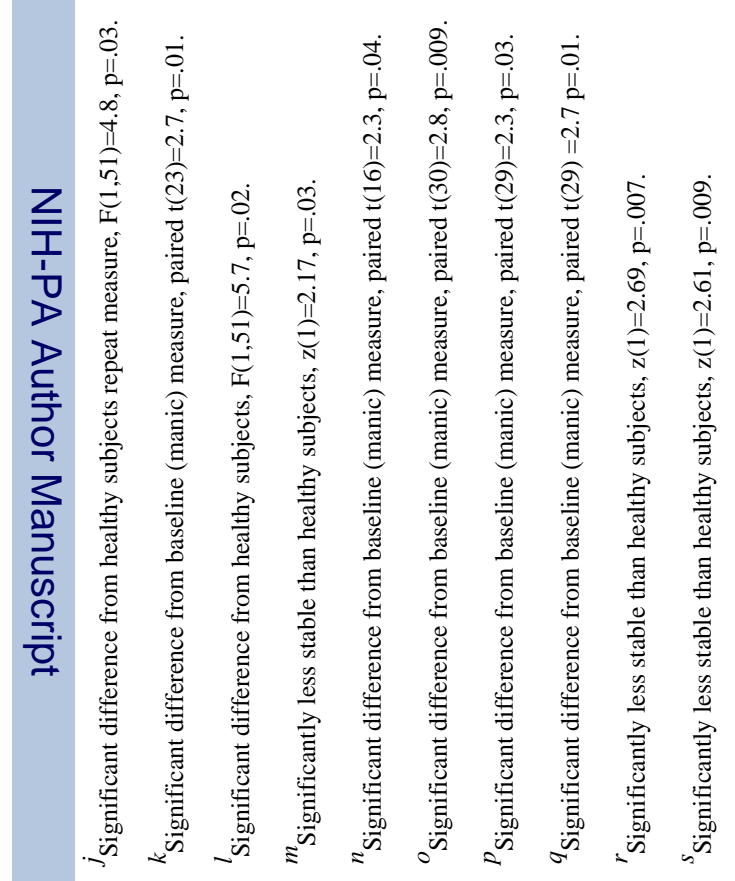




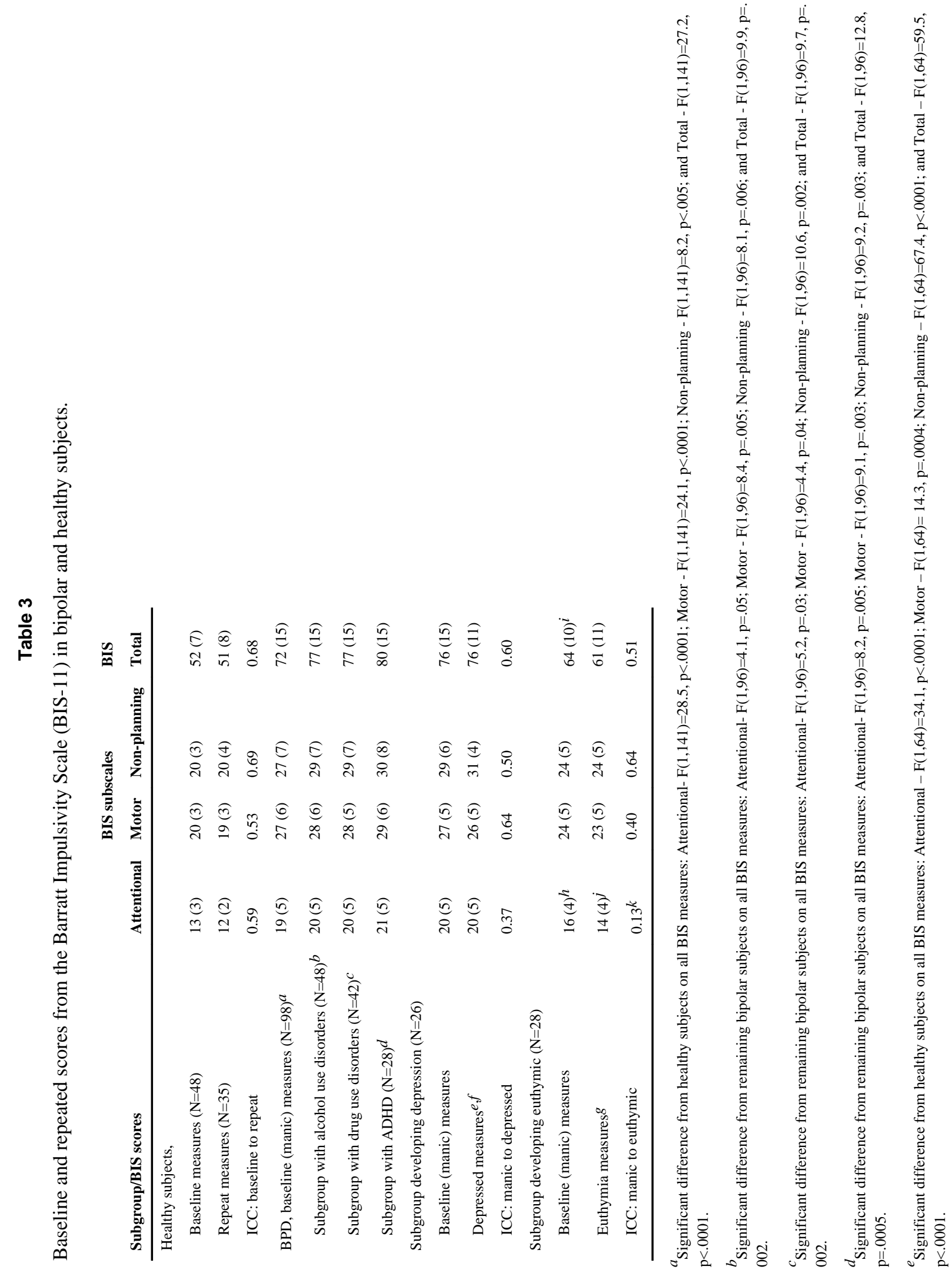




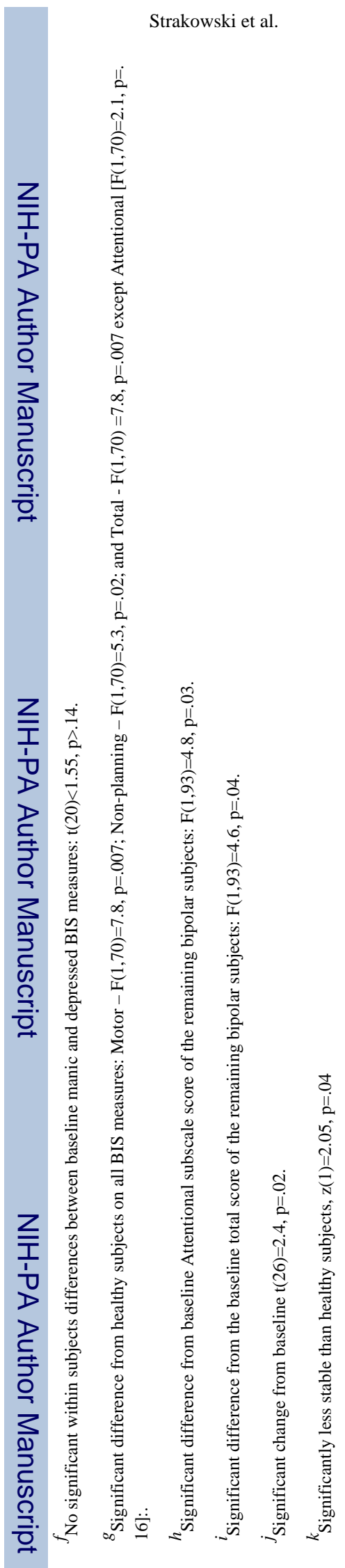

Bipolar Disord. Author manuscript; available in PMC 2010 August 18. 